\title{
Grupo de Pesquisa em Informática na Educação
}

\author{
Patrícia B. Scherer Bassani ${ }^{1}$, Débora Nice F. Barbosa ${ }^{1}$, Regina de O. Heidrich ${ }^{1}$, \\ Sandra P. Montardo ${ }^{1}$
}

${ }^{1}$ Programa de Pós-Graduação em Diversidade Cultural e Inclusão Social - Universidade Feevale - ERS 239, 2755 - Novo Hamburgo/RS - Brasil

\{patriciab, deboranice, rheidrich, sandramontardo\}efeevale.br

\section{Apresentação do grupo de pesquisa}

O Grupo de Pesquisa em Informática na Educação, certificado no CNPq pela Universidade Feevale, se constitui a partir de uma abordagem interdisciplinar, articulando pesquisas nas áreas de Informática, Educação, Comunicação, Design e Psicologia. Seu objeto de investigação são as tecnologias da informação e comunicação, enfocando o uso do computador nos processos de ensino e de aprendizagem e a constituição de redes sociais na web. Dessa forma, as temáticas de pesquisa propostas contemplam comunidades virtuais de aprendizagem, inclusão e acessibilidade digital, educação a distância, interação homem-computador, o consumo mediado por computador e o uso de computadores no ensino e suas implicações educacionais. $\mathrm{O}$ grupo se organiza a partir de duas linhas de pesquisa: Inclusão e acessibilidade digital e Tecnologia da informação aplicada à educação. Também se articula com o Programa de Pós-Graduação em Diversidade Cultural e Inclusão Social por meio da linha de pesquisa Linguagens e Tecnologias.

Os professores-pesquisadores que coordenam projetos são: Profa. Dra. Patrícia B. S. Bassani (líder do grupo), Profa. Dra. Débora Nice F. Barbosa, Profa. Dra. Regina Heidrich e Profa. Dra. Sandra Montardo. A equipe é composta por alunos de iniciação científica, mestrado e doutorado, além de professores colaboradores. Os projetos em andamento são: a) Comunidade Virtual de Aprendizagem e Gamificação (CNPq/MinC/ SEC No 80/2013 Eixo Temático - Inovação em Cultura); b) Integrando tecnologias e potencializando ações em direção à um ambiente lúdico de aprendizagem voltado ao reforço escolar de crianças e adolescentes em tratamento oncológico (Universal CNPq 2013); c) Aprendizagem Lúdica, Colaborativa e com Mobilidade: análise do impacto do uso de jogos, tecnologias móveis e ambientes virtuais de aprendizagem no processo de ensino e aprendizagem de crianças e adolescentes em tratamento oncológico (bolsa DT CNPq Débora Barbosa); d) Ensinar e aprender em/na rede: a arquitetura de participação da web 2.0 no contexto da educação presencial (MCTI/CNPq/ MEC/CAPES No 18/2012); e) Práticas pedagógicas no ciberespaço: interação e cooperação na web com desktops, laptops e tablets nos anos iniciais do ensino fundamental (Universal CNPq 2013); f) Desenvolvimento de softwares baseados em Brain Computer Interface para auxiliar pessoas com limitações motoras no processo de inclusão escolar (CNPq/SEC/MinC N. ${ }^{\circ}$ 80/2013); g) Vocalizer F2: Desenvolvimento de um scanner de mesa com voz, (MCTI/SECIS/Finep/FNDCT, Cooperação ICT - Empresa - Tecnologia Assistiva - 01/2013); h) Desenvolvimento de softwares baseados em Brain Computer Interface para auxiliar pessoas com limitações motoras no processo de inclusão escolar (MCTI-SECIS/CNPq - Tecnologia assistiva/B-Núcleos Emergentes); i) Consumo como performance em sites de redes sociais (MCTI/CNPq/MEC/CAPES No. 43). 